\section{Stomach rinsing in rays}

he vomiting reflex is a protective mechanism for the bulk ejection of noxious material, and is common in vertebrates ${ }^{1}$. Here we show that the thornback ray Raja clavata (Rajidae) can 'rinse' its stomach by full gastric eversion, washing small indigestible food particles and sloughed gastric mucosa and mucus out of the upper digestive tract. This may be a widespread mechanism, besides vomiting, for fish to remove noxious material from the stomach.

Skates and rays are ubiquitous and comprise nearly half the 900 known species of Elasmobranchii (sharks, skates and rays). We studied the vomiting responses of $R$. clavata caught in the English Channel and fed on chopped fish and squid in the laboratory. Individual $R$. clavata were given an emetic $^{1}$, veratrine hydrochloride $(10 \mathrm{mg}$ $\mathrm{kg}^{-1}$ i.p. in elasmobranch ringer; $n=4$ ), or ringer $(n=3)$. After injection we placed them in a glass-sided tank and recorded their behaviour on video.

Stomach eversion and swallowing of the everted stomach occurred within $10 \mathrm{~min}$ of drug injection, but not in rays given ringer. Eversion was frequent: in one animal, it occurred nine times in four discrete bursts post-injection (three eversions between 351 and $361 \mathrm{~s}$; one at $404 \mathrm{~s}$; three between 425 and $430 \mathrm{~s}$; two at $463 \mathrm{~s}$ ). Immediately before eversion, the mouth was wide open, the jaws protruded and the buccal and pharyngeal cavities expanded (Fig. 1). The stomach prolapsed and was fully everted $0.5-2.0 \mathrm{~s}$ later, concomitant with a strong contraction of the pharynx. The outline of the hypo- and basi-branchial cartilages under the skin was visible externally, indicating contraction of the coraco-mandibularis, -hyoideus and -branchiales muscles (see frame 7:08:51).

The entrance to the pylorus on the stomach's mucosal surface was visible, indicating that the stomach was fully everted. This was accompanied by lateral shaking of the head, a behaviour also seen in vomiting dogfish ${ }^{1}$. Between 0.2 and $2.0 \mathrm{~s}$ later, when the pharyngeal cavity expanded, the stomach was retracted into the mouth. We assume that it was swallowed in the next $0.1-0.2 \mathrm{~s}$, as it was not visible inside the oral cavity, and maximal jaw protrusion and mouth closure followed rapidly - behaviour consistent with the normal prey-capture responses of rays before swallowing. The material ejected ranged from small pieces of fish to a particulate mucoid suspension.

These observations show that rays evert and swallow their stomachs in response to an agent that induces vomiting in other fish (such as dogfish) ${ }^{1}$ and vertebrates (such as

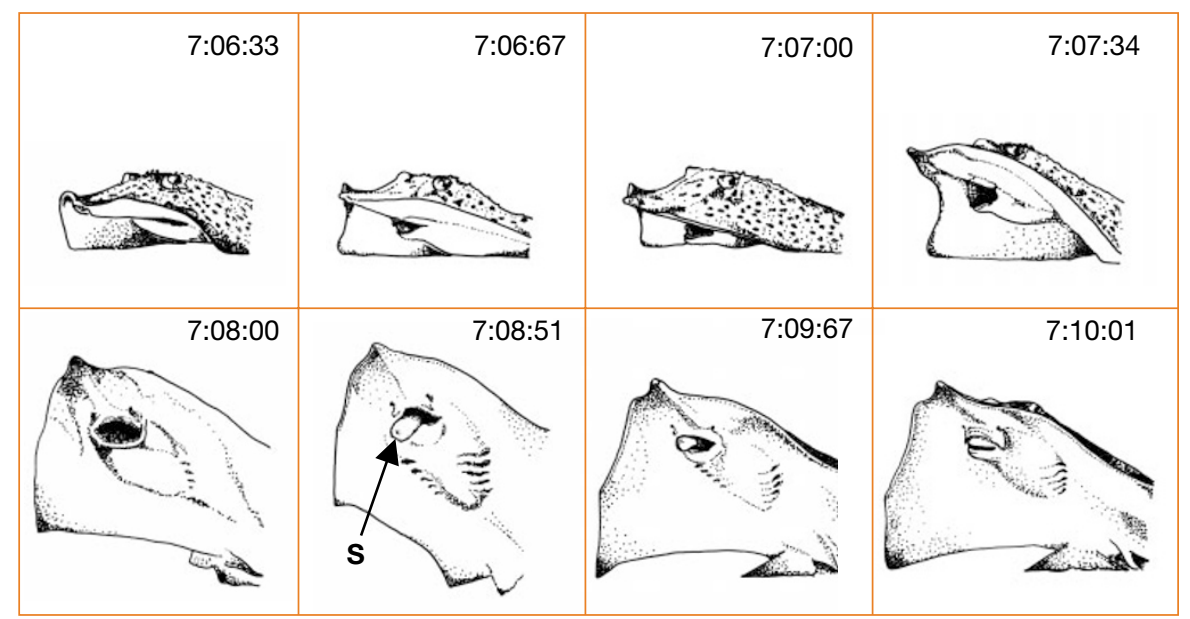

Figure 1 Temporal sequence of stomach eversion and swallowing in Raja clavata. Number in each frame refers to elapsed time (minutes: seconds: hundredths of a second) from injection of veratrine. S, cardiac stomach. Video recordings of behaviour were analysed by taking monochrome digitalized still images, constituting individual frames, from the videotape at selected time intervals using a Pana sonic NVMP1 video printer.

crocodiles and cats) ${ }^{2,3}$. We do not know how the stomach is everted, but it probably involves profound relaxation of the gastric musculature and a rapid increase in intraabdominal pressure. Some amphibians also prolapse the oesophagus and stomach through the mouth during vomiting ${ }^{4,5}$, and intense abdominal muscle contraction has been reported as the mechanism for oral eversion in ten species of frogs and toads ${ }^{6}$.

Post-mortem studies of wild-caught rays $(n=6)$ show that oral eversion of the stomach could be induced by gas inflation of the peritoneal cavity using a pressure of about $200 \mathrm{~mm} \mathrm{Hg}$. We also found that chitinous food residues, such as prawn exoskeletons, and larger pieces of fish can also be ejected by this procedure.

In rays, the oral eversion of the stomach is not impeded by mesenteric attachments of the gut to the body wall ${ }^{7}$. The short distance from the mouth to the stomach and the short, wide oesophagus - common to both rays and frogs and toads - presumably act to facilitate eversion.

Cloacal protrusion of the valvular intestine in rays could not be induced by peritoneal inflation, although it can be in members of the shark family Carcharhinidae ${ }^{8}$. There are no descriptions of vomiting in these species, but fishermen have observed line- and net-caught sharks with everted stomachs, possibly due to capture; however, post-eversion stomach swallowing has not been recorded ${ }^{9}$.

Nonetheless, there is anecdotal evidence that stomach eversion and swallowing occurs in three carcharhinid shark species (Carcharhinus cautus, Negaprion brevirostris, Prionace glauca) and a guitarfish (Rhinobatos typus) (C. Grist, J. Ugoretz and W. White, personal communication). A lemon shark, $N$. brevirostris, was seen to evert its stomach naturally, where it hung limply out of one side of the mouth before head-shaking released an oily 'scum' from the surface of the stomach, which was then swallowed. The whole episode lasted 25-30 seconds.

We suggest that sharks and rays can externalize most of their alimentary canal, and that this process serves to remove parasites, indigestible material, toxic food, and last of these could also be used to excrete accumulated toxic metabolites - as in chinstrap penguins, which excrete fluoride by vomiting their stomach linings ${ }^{10}$. In frogs and toads, stomach eversion is accompanied by 'gastric grooming' with the right hand to wipe away vomitus ${ }^{6}$. We propose that rays' head-shaking during oral eversion fulfils a similar function, and rinses the stomach of persistent small particles and mucus.

David W. Sims ${ }^{\star}$, Paul L. R. Andrews $\dagger$, J. Z. Young $\ddagger$

${ }^{*}$ Department of Zoology, University of Aberdeen,

Tillydrone Avenue, Aberdeen AB24 2TZ, UK

e-mail:d.w.sims@abdn.ac.uk

$\dagger$ Department of Physiology, St George's Hospital Medical School, Cranmer Terrace, London

SW17 ORE, UK

$\ddagger$ Department of Experimental Psychology, University of Oxford, South Parks Road, Oxford OX1 3UD, UK

$\$$ Deceased

1. Andrews, P. L. R., Sims, D. W. \& Young, J. Z. J. Mar. Biol. Assoc. UK 78, 1269-1280 (1998)

2. Andrews, P. L. R. et al. J. Exp. Biol. (in the press).

3. Borison, H. L. \& Fairbanks, V. F. J. Pharmacol. Exp. Therapeut. 105, 317-325 (1952).

4. Naitoh, T. \& Wassersug, R. J. Nature 380, 30-31 (1996).

5. Naitoh, T. et al. Physiol. Zool. 62, 819-843 (1989).

6. Naitoh, T., Imamura, M. \& Wassersug, R. J. Comp. Biochem. Physiol. 100C, 353-359 (1991).

7. Wake, M. H. (ed.) Hyman's Comparative Vertebrate Anatomy (Univ. Chicago Press, Chicago, 1979).

8. Crow, G. L. et al. Copeia 1990, 226-229 (1990).

9. Budker, P. The Life of Sharks (Weidenfeld \& Nicolson, London, 1971).

10. Beintema, A. J. Nature 352, 480-481 (1991). retracted slowly through the mouth and sloughed gastric mucosa and mucus. The 